\title{
A case of Takotsubo cardiomyopathy with cardiogenic shock after influenza infection successfully recovered by IMPELLA support
}

\author{
Makiko Nakamura $^{1}$ (1) $\cdot$ Masaki Nakagaito $^{1} \cdot$ Masakazu Hori $^{1} \cdot$ Hiroshi Ueno ${ }^{1} \cdot$ Koichiro Kinugawa $^{1}$
}

Received: 1 May 2019 / Accepted: 15 June 2019 / Published online: 21 June 2019

(c) The Japanese Society for Artificial Organs 2019

\begin{abstract}
We recently experienced a case of cardiogenic shock due to influenza-related Takotsubo cardiomyopathy with atrial tachycardia and respiratory distress syndrome. Temporary mechanical circulatory support by IMPELLA 2.5 improved end-organ failure and resulted in cardiac recovery with sinus rhythm conversion.
\end{abstract}

Keywords Ventricular assist device $\cdot$ Supraventricular tachycardia $\cdot$ Stress cardiomyopathy $\cdot$ Mechanical circulatory support

\section{Introduction}

Takotusbo cardiomyopathy is characterized by transient systolic and diastolic left ventricular dysfunction with a variety of wall motion abnormalities and often preceded by emotional or physical trigger. In the acute phase of Takotsubo cardiomyopathy, patients often represent an acute heart-failure syndrome [1] and in-hospital mortality is about 4-5\%, a figure comparable to that of ST elevation myocardial infarction [2]. Among the patients with Takotsubo cardiomyopathy, concentrations of plasma catecholamine and stress-related circulating neuropeptides were several times higher than those in patients with myocardial infarction and remained elevated even a week after the onset of symptoms [3]. Such catecholamine surge may lead to myocardial damage [4]. Here, we present a case of Takotsubo cardiomyopathy with left ventricular dysfunction and atrial tachycardia after influenza who had compromised hemodynamics despite intravenous inotropes and eventually required mechanical support (IMPELLA 2.5). After 4 days'

Electronic supplementary material The online version of this article (https://doi.org/10.1007/s10047-019-01112-8) contains supplementary material, which is available to authorized users.

Makiko Nakamura

nakamura@med.u-toyama.ac.jp

1 Second Department of Internal Medicine, University of Toyama, 2630 Sugitani, Toyama 930-0194, Japan support of IMPELLA, his left ventricular systolic function recovered to normal range with sinus rhythm conversion. Hemodynamic support and left ventricular unloading by IMPELLA were helpful for cardiac recovery of Takotsubo cardiomyopathy.

\section{Case report}

The patient was a Japanese 82-year-old gentleman who was admitted to our hospital for disturbance of consciousness with slight fever $\left(37.4^{\circ} \mathrm{C}\right)$. Although head MRI did not show typical findings of encephalitis, such as cortical high signal of the brain, he was suspected of encephalopathy due to influenza A infection, and was given peramivir hydrate $(300 \mathrm{mg})$ and methylprednisolone pulse therapy ( $1 \mathrm{~g}$ daily for 3 days) on emergency department. On admission, he was hypertensive (220/125 mmHg) and EKG showed sinus tachycardia with ST changes in multiple leads (Fig. 1a). Cardiac troponin I was elevated, but cardiac enzymes were within normal limit. On the 2nd day, his heart rate (HR) was elevated to $160-180 \mathrm{bpm}$ and $2 \mu \mathrm{g} / \mathrm{kg} / \mathrm{min}$ of landiolol was administered. On the 4th day, he became hypoxic, and chest X-ray showed bilateral pulmonary infiltration, and he was suspected of pneumonia and acute respiratory distress syndrome. On the 5th day, he became hypotensive $(87 / 45 \mathrm{mmHg})$ with atrial tachycardia, and fluid replacement was administered. EKG showed inverted $\mathrm{T}$ wave in broad leads (Fig. 1b). Transthoracic echocardiography revealed 
(A)

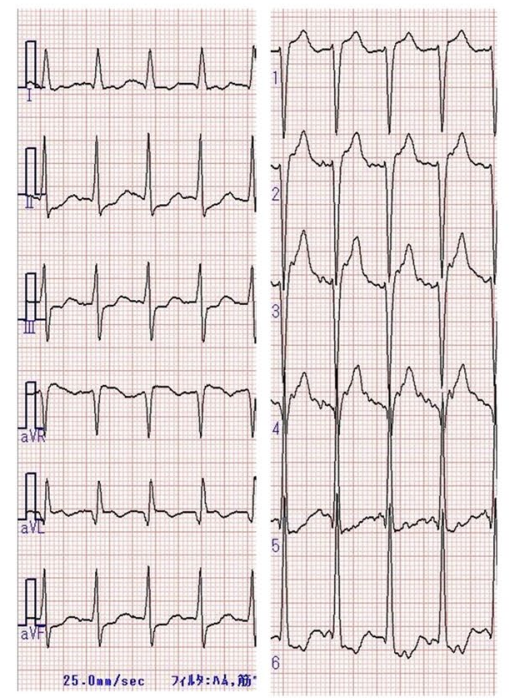

(B)

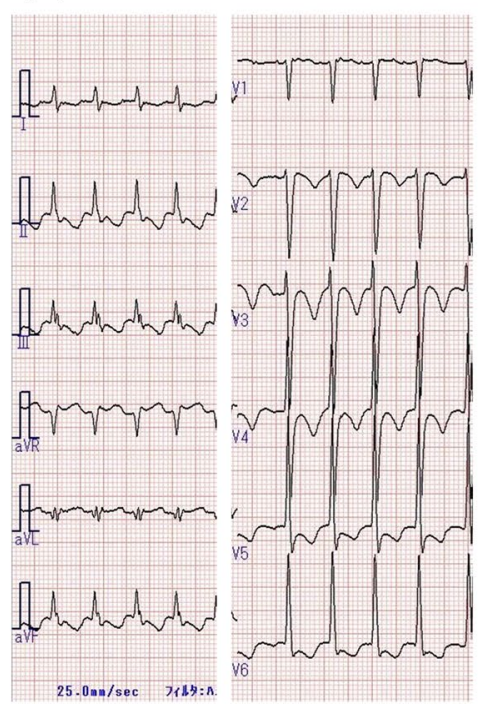

(C)

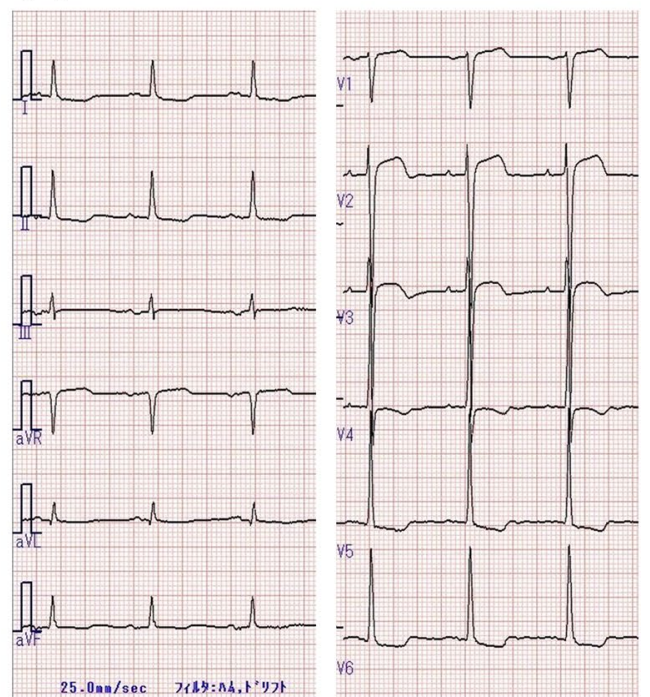

Fig. 1 Changes of electrocardiogram during the hospitalization. a Was on admission, $\mathbf{b}$ was on the 8th day, and $\mathbf{c}$ was on the 13th day

reduced left ventricular ejection fraction of $34 \%$ with severe hypokinesis in the antero-apical wall in contrast to hyperkinetic region in the base (Fig. 2a). No outflow obstruction or no significant valvulopathy was observed, and left ventricular diastolic dimension was $44 \mathrm{~mm}$. BNP level was high as $634 \mathrm{pg} / \mathrm{mL}$ on the 6 th day and intravenous dobutamine infusion of $2 \mu \mathrm{g} / \mathrm{kg} / \mathrm{min}$ and furosemide $10-20 \mathrm{mg}$ daily were administered. Intravenous landiolol was increased to $5 \mu \mathrm{g} / \mathrm{kg} / \mathrm{min}$ for supraventricular tachycardia. On the $7 \mathrm{th}$ day, intravenous dobutamine was increased to $2.5 \mu \mathrm{g} / \mathrm{kg} /$ min and intravenous amiodarone infusion (150 mg per day) was also administered. On the 8th day, his consciousness improved and he was transferred from the department of neurology to our ward for intensive care of heart failure. Cardiac catheterization showed mean right atrial pressure of $8 \mathrm{mmHg}$, pulmonary artery pressure of $31 / 23$, and mean pulmonary artery wedge pressure of $15 \mathrm{mmHg}$, respectively. Cardiac output (CO) and cardiac index (CI) were $3.18 \mathrm{~L} / \mathrm{min}$ and $1.95 \mathrm{~L} / \mathrm{min} / \mathrm{m}^{2}$, respectively, and mixed venous oxygen saturation $\left(\mathrm{SvO}_{2}\right)$ was low as $49.5 \%$. Left
(A)
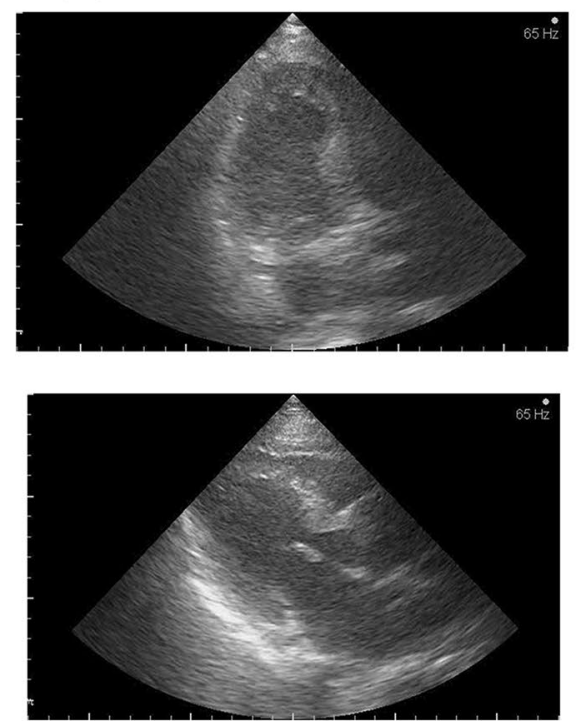

(B)

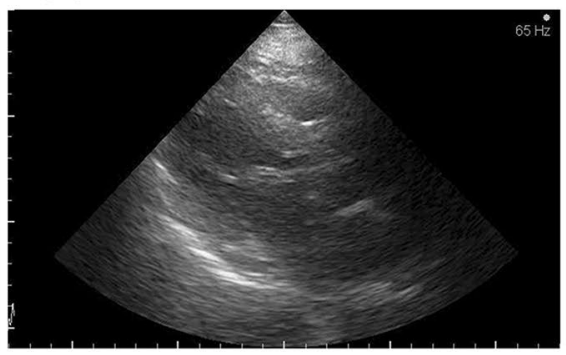

(C)
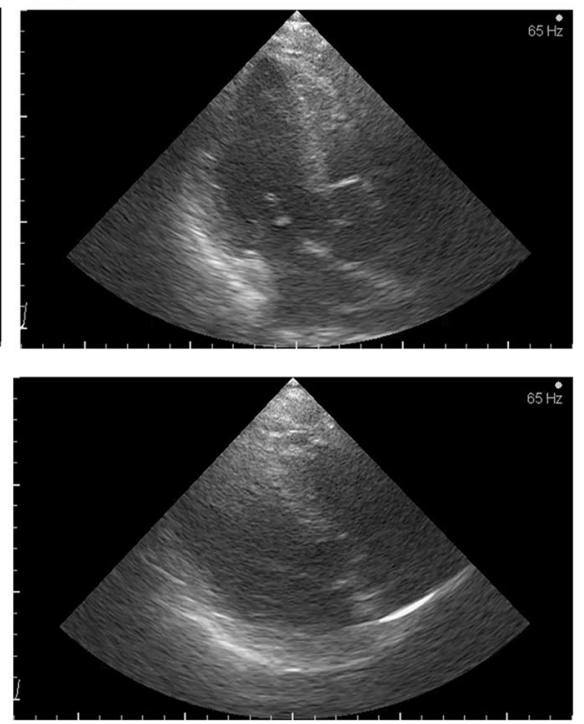

Fig. 2 Apical three-chamber view on transthoracic echocardiography. a Was on the 6th day, b was on the 8th day during IMPELLA support, and c was on the 29 th day 
ventricular end-diastolic pressure (LVEDP) was elevated to $23 \mathrm{mmHg}$ and systolic blood pressure was $120-130 \mathrm{mmHg}$ when HR was $160-170 \mathrm{bpm}$, but was low as $70-80 \mathrm{mmHg}$ when HR reached to 190-200 bpm. Coronary angiogram showed no organic stenosis, and myocardial biopsy showed no inflammatory cell infiltration nor eosinophils or giant cells. Accordingly, we diagnosed him as influenza-related Takotsubo cardiomyopathy. In spite of intensive medical treatment, his hemodynamics was still compromised with elevated lactate level of $3.2 \mathrm{mmol} / \mathrm{L}$. Atrial tachycardia did not resolve even by DC cardioversion. Then, we decided to insert IMPELLA 2.5 from his right femoral artery as a temporary mechanical circulatory support on the 8th day (Fig. 2b). After insertion of IMPELLA, pulmonary artery diastolic pressure was decreased to $6 \mathrm{mmHg}$, and $\mathrm{CO}$ and $\mathrm{SvO}_{2}$ were increased to $4.0 \mathrm{~L} / \mathrm{min}$ and $52 \%$, respectively. Lung congestion and infiltrations were gradually improved. Left ventricle wall motion improvement was also found by echocardiography on the 11th day, and IMPELLA was eventually removed on the 12th day (Fig. 3). During IMPELLA support, there was no device-related adverse event. He spontaneously restored sinus rhythm on the 13th day (Fig. 1c) and left ventricular ejection fraction improved to $55 \%$ with no asynergy (Fig. 2c). He was discharged with BNP of $29.2 \mathrm{pg} / \mathrm{mL}$ on the 35 th day.

\section{Discussion}

In this report, we described a case of 82-year-old Takotsubo cardiomyopathy after influenza infection. Though he was complicated with impaired consciousness, congestive heart failure, refractory tachyarrhythmia, and acute respiratory distress syndrome, IMPELLA support markedly improved his hemodynamics and he was rescued with complete cardiac recovery.

On admission, his EKG resembled to acute coronary syndrome with elevated cardiac troponin I, but we did not perform coronary angiogram considering his age and possible brain damage. Over the next couple of days, he became hypotensive and hypoxic with emergence of atrial tachycardia. He was initially suspected of influenza-related myocarditis, but myocardial biopsy revealed no signs of myocarditis. In consideration of echocardiographic findings, we then diagnosed as Takotsubo cardiomyopathy. Different emotional and psychological stressors have been identified to precede of the onset of Takotsubo syndrome. Acute stressors induce brain activation, increasing bioavailability of cortisol and catecholamine. This catecholamine surge leads direct catecholamine toxicity, adrenoceptor-mediated damage, epicardial and

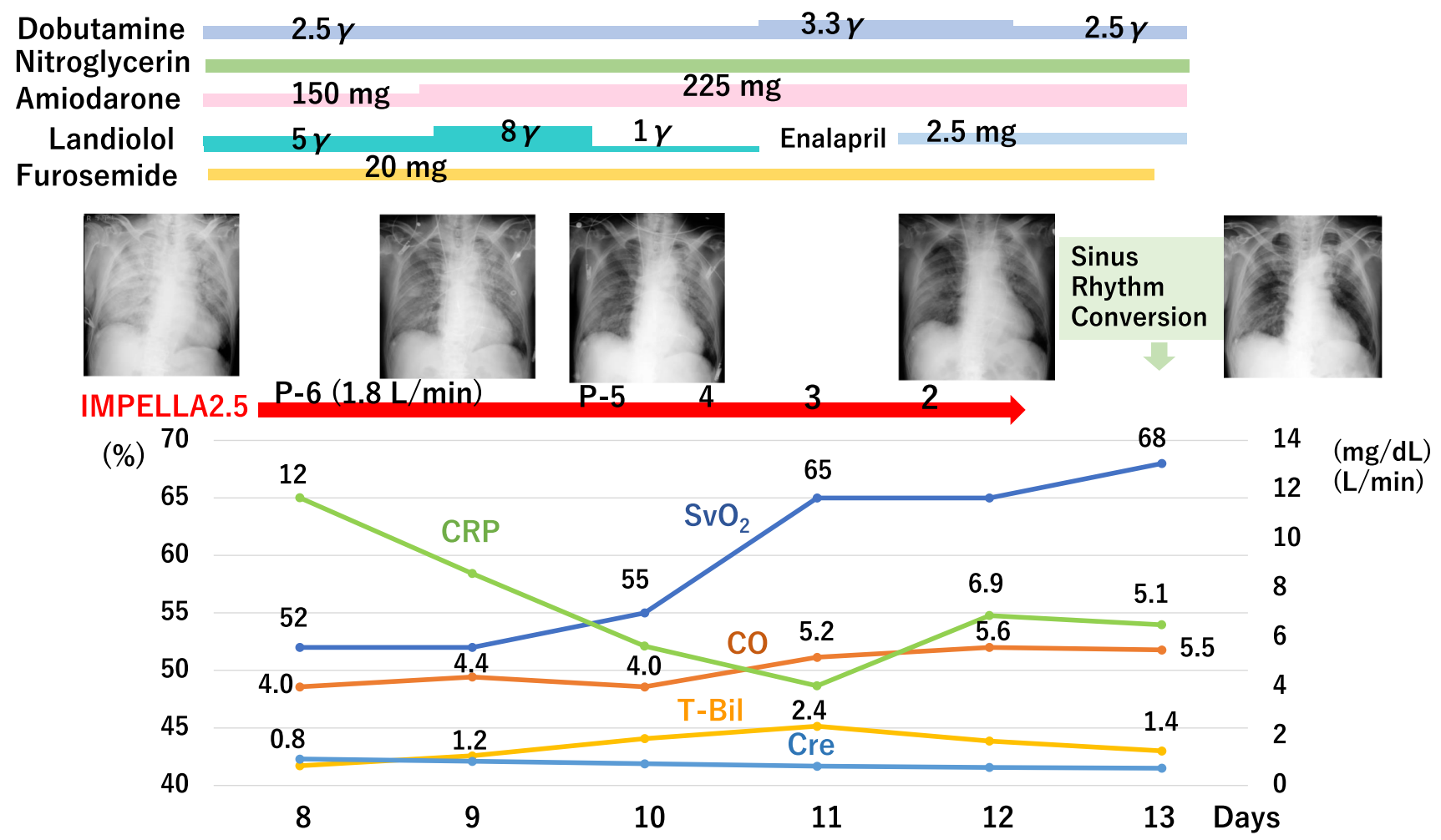

Fig. 3 Clinical course after IMPELLA 2.5 insertion. The dose of administered drugs was also shown. CRP C-reactive protein, $T$-Bil total bilirubin, $\mathrm{Cre}$ serum creatinine, $\mathrm{SvO}_{2}$ mixed venous oxygen saturation, $\mathrm{CO}$ cardiac output 
microvascular coronary vasoconstriction and/or spasm, and increased cardiac workload, to myocardial damage [4]. In this case, the physical stress of influenza infection was highly attributable to the development of Takotsubo syndrome. The plasma concentration of noradrenaline was high as $1047 \mathrm{pg} / \mathrm{mL}(100-450 \mathrm{pg} / \mathrm{mL})$ on the 8th day, and slightly decreased to $732 \mathrm{pg} / \mathrm{mL}$ on the 12 th day. Myocardial involvement during influenza virus infection has been described in $10 \%$ of cases [5] and the cases of Takotsubo cardiomyopathy triggered by Influenza A or B have also been known $[6,6]$. Once he was diagnosed as Takotsubo cardiomyopathy, we had to avoid increasing the dose of intravenous inotropes because of the nature of this disease. Therefore, we decided to use temporary mechanical support. IABP may be one of the options, but his heart rate was too fast to be followed by IABP. Considering his wet lung, V-A ECMO may not be a wise option either. On the other hand, IMPELLA ameliorates pulmonary congestion by reducing LV preload and increases cardiac output regardless of HR [8]. Therefore, IMPELLA was considered as the best choice in this setting. A case of cardiogenic shock secondary to Takotsubo cardiomyopathy rescued by IMPELLA 2.5 was previously reported [9]. Beneduce A. et al. also reported the usefulness of IMPELLA for Takotsubo syndrome complicated with cardiogenic shock and left ventricular outflow obstruction [10]. However, we believe that this is the first IMPELLA case of Takotsubo cardiomyopathy in a Japanese patient.

In summary, an 82-year-old patient with acute heart failure due to influenza-related Takotsubo cardiomyopathy was safely treated with IMPELLA 2.5 and successfully obtained cardiac recovery.

\section{Compliance with ethical standards}

Conflict of interest All authors have no conflict of interest.

\section{References}

1. Templin C, Ghadri JR, Diekmann J, et al. Clinical features and outcomes of Takotsubo (Stress) CARDIOMYOPATHY. N Engl J Med. 2015;373:929-38.

2. Tornvall P, Collste O, Ehrenborg E, et al. A case-control study of risk markers and mortality in Takotsubo stress cardiomyopathy. $\mathrm{J}$ Am Coll Cardiol. 2016;67:1931-6.

3. Wittstein IS, Thiemann DR, Lima JA, et al. Neurohumoral features of myocardial stunning due to sudden emotional stress. N Engl J Med. 2005;352:539-48.

4. Pelliccia F, Kaski JC, Crea F, et al. Pathophysiology of Takotsubo syndrome. Circulation. 2017;135:2426-41.

5. Mamas MA, Fraser D, Neyses L. Cardiovascular manifestations associated with influenza virus infection. Int J Cardiol. 2008;130:304-9.

6. Buzon J, Roignot O, Lemoine S, et al. Takotsubo cardiomyopathy triggered by influenza A virus. Intern Med (Tokyo, Japan). 2015;54:2017-9.

7. Golfeyz S, Kobayashi T, Aoi S, et al. Possible association of influenza A infection and reverse takotsubo syndrome. BMJ case Rep. 2018;11:e226289.

8. Lima B, Kale P, Gonzalez-Stawinski GV, et al. Effectiveness and safety of the Impella 5.0 as a bridge to cardiac transplantation or durable left ventricular assist device. Am J Cardiol. 2016;117:1622-8.

9. Rashed A, Won S, Saad M, et al. Use of the Impella 2.5 left ventricular assist device in a patient with cardiogenic shock secondary to Takotsubo cardiomyopathy. BMJ Case Rep. 2015. https://doi. org/10.1136/bcr-2014-208354.

10. Beneduce A, Fausta Bertoldi L, Melillo F, et al. Mechanical circulatory support with impella percutaneous ventricular assist device as a bridge to recovery in Takotsubo syndrome complicated by cardiogenic shock and left ventricular outflow tract obstruction. JACC Cardiovasc Interv. 2019;12:e31-e2.

Publisher's Note Springer Nature remains neutral with regard to jurisdictional claims in published maps and institutional affiliations. 